\title{
Interferensi Bahasa Betawi Dalam Teks Eksposisi Bahasa Indonesia Siswa Kelas VIII SMP Negeri 17 Di Depok
}

\author{
Aster Pujaning Ati, Deni Nasir Ahmad \\ Universitas Indraprasta PGRI, Jakarta
}

\begin{abstract}
asterpujaningati@ymail.com
ABSTRAK

Tujuan penelitian ini adalah untuk mengetahui bentuk interferensi bahasa Betawi pada tataran morfologi dalam karangan eksposisi bahasa Indonesia siswa kelas VIII SMP Negeri 17 di Kota Depok. Penelitian ini menggunakan metode kualitatif, karena penelitian kualitatif merupakan penelitian yang paling cocok untuk menganalisis kebahasaan. Teknik pengumpulan data menggunakan metode simak. Tekniknya yang digunakan yaitu metode pustaka dengan membagi wacana menjadi beberapa kalimat untuk dikelompokkan dan dianalisis berdasarkan unsur pembentuknya kemudian diteruskan menggunakan teknik dasar sadap dan teknik lanjutannya teknik catat.Pada penelitian ini jumlah sampel sepertiga jumlah karangan dari satu sekolah Unsur interferensi morfologi ditemukan terdapat di 84 kalimat dari 260 kalimat atau dapat di persentasekan sebesar $32.3 \%$. Berdasarkan analisis aspek morfologi yang sering muncul adalah perubahan vokal dan konsonan digunakan oleh peserta didik sebanyak 18 kali atau 6.9\%. Penghilangan vokal dan konsonan yang digunakan peserta didik sebanyak 10 kalimat atau $3.8 \%$. Sedangkan yang paling jarang muncul adalah penggunaan reduplikasi dan diftong dimana masingmasing hanya terjadi 6 kali atau $2.3 \%$.

Kata kunci: Interferensi, Morfologi, Eksposisi
\end{abstract}

\section{DIDACTICAL VALUE IN JEJAK-JEJAK MISTERIUS TALES COLLECTION}

\begin{abstract}
The purpose of this study was to determine the form of Betawi language interference at the morphological level in the Indonesian language exposition essay for eighth grade students of SMP Negeri 17 in Depok City. This research uses qualitative methods, because qualitative research is the most suitable research for analyzing language. The data collection technique used the observation method. The technique used is the library method by dividing discourse into several sentences to be grouped and analyzed based on the constituent elements then continued using the basic tapping technique and the advanced technique of note taking. In this study the sample size is one-third of the number of essays from one school. Morphological interference elements were found in 84 sentences. of 260 sentences or can be in percentage of $32.3 \%$. Based on the analysis of the morphological aspects that often appear is the change in vowels and consonants used by students 18 times or $6.9 \%$. The elimination of vowels and consonants used by students was 10 sentences or $3.8 \%$. Meanwhile, the most rare occurrences were the use of reduplication and diphthong, where each only occurred 6 times or $2.3 \%$.
\end{abstract}

Keywords: Interferensi, Morfologi, Eksposisi

\section{PENDAHULUAN}


Arah pembelajaran Bahasa Indonesia sesuai dengan kurikulum pada tingkat SMP untuk meningkatkan kemampuan peserta didik berkomunikasi dalam bahasa Indonesia dengan baik dan benar, baik secara lisan maupun tulis. Serta menumbuhkan apresiasi terhadap hasil karya kesusastraan Indonesia. Bahasa yang baik adalah bahasa yang digunakan sesuai dengan norma kemasyarakatan, sedangkan bahasa yang benar adalah bahasa yang digunakan sesuai dengan aturan atau kaidah tata bahasa baku. Jadi dapat disimpulkan bahasa yang baik dan benar itu adalah bahasa yang digunakan sesuai dengan norma kemasyarakatan dan kaidah tata bahasa baku.

Mata pelajaran Bahasa Indonesia mencakup empat keterampilan yaitu, mendengarkan, berbicara, membaca dan menulis. Diharapkan siswa dapat menguasai empat keterampilan tersebut agar tidak merasa kesulitan untuk mengikuti pelajaran Bahasa Indonesia pada jenjang pendidikan berikutnya. Namun, untuk keterampilan menulis perlu latihan yang terus menerus. Keterampilan menulis menuntut seseorang dapat menggunakan pola-pola untuk mengungkapkan pikiran, ide atau pendapat yang disusun secara sistematis dan logis dalam bentuk tulisan. Atar Semi mengemukakan bahwa menulis merupakan proses kreatif memindahkan gagasan ke dalam lambang-lambang tulisan (Semi, 2007:14). Jadi menulis merupakan kegiatan yang kreatif. Ide yang kreatif sangat diperlukan dalam menulis. Melalui tulisan yang kreatif, seseorang akan dapat membuat tulisan yang menyenangkan untuk dibaca.

Bahasa Indonesia, untuk sebagian besar daerah di Indonesia, merupakan bahasa kedua (B2) dan diajarkan di sekolah-sekolah. Bahasa pertama mereka adalah bahasa daerah. Pada saat seseorang belajar bahasa kedua sering dipengaruhi oleh bahasa pertama (B1). Seperti yang dikemukakan oleh Brown "The native language of learners exerts strom influence on the acquistion

of the target language system. While that native system will exercise both facilitating and interfering effects on the production and comprehension of the new language, the interfering effect are likely to be the most salient.(Brown, 2001: 66)." Brown menyimpulkan bahwa hubungan yang erat dari penelitian bahasa kedua, baik anak-anak maupun orang dewasa difokuskan pada pengaruh bahasa pertama dan bahasa kedua itu sendiri.

Dalam proses pembelajarannya ada beberapa tipe pembelajaran bahasa. Ellis menyebutkan Ada dua tipe pembelajaran bahasa yang diperoleh anak, yaitu tipe naturalistik dan tipe formal di dalam kelas (Ellis dalam Chaer, 2002).Yang pertama tipe naturalistik bersifat alamiah, tanpa guru dan tanpa kesengajaan. Pembelajaran berlangsung di dalam lingkungan kehidupan bernasyarakat. Seorang anak yang di dalam lingkungan keluarganya menggunakan Bahasa perrtama (B1) misalnya bahasa X, begitu keluar dari rumah berjumpa dengan temanteman lain yang menggunakan bahasa $\mathrm{Y}$ misalnya, akan mencoba dan berusaha menggunakan bahasa Y. Tipe kedua, yang bersifat formal berlangsung didalam kelas dengan guru, materi, dan alat-alat bantu belajar yang sudah dipersiapkan.

Interferensi pertama kali digunakan oleh Weinreich untuk menyebutkan adanya perubahan sistem suatu bahasa sehubungan dengan adanya persentuhan bahasa tersebut dengan

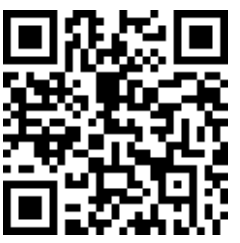

DOI PUBLIKASI https://doi.org/10.37010/int.v1i2 
unsur-unsur bahasa lain yang dilakukan oleh penutur dua bahasa (Chaer dan Agustina, 2002). Hartman dan Stork mengatakan bahwa interferensi sebagai "kekeliruan" yang disebabkan oleh terbawanya kebiasaan-kebiasaan ujaran bahasa atau dialek ibu ke dalam bahasa atau dialek kedua (Alwasilah dalam Mustofa,2018). Interferensi sebagai suatu "pengacauan" yang terjadi pada penutur dua bahasa yang disebabkan karena penguasaan bahasa yang tidak seimbang. Penguasaan bahasa yang tidak seimbang dapat terjadi pada kemajemukan bilingual.

Kemajemukan ini terjadi karena pemahaman terhadap dua bahasa tidak seimbang sehingga salah satu lebih dominan meskipun yang digunakan adalah bahasa yang lain (Nababan,1991). Interferensi dapat terjadi pada tataran kebahasaan seperti pada tataran fonologi, morfologi, leksikal, sintaksis, dan semantis. Interferensi dalam penelitian ini lebih ditekankan pada interferensi morfologis, leksikal, dan sintaksis. Dalam penelitian ini, interferensi dianalisis berdasarkan jenis interferensi yang dikemukakan oleh Weinreich (1970), yaitu salah satunya adalah interferensi morfologis. Interferensi morfologis biasa disebut juga dengan interferensi gramatikal. Interferensi morfologis terjadi apabila dalam pembentukan kata, suatu bahasa menyerap afiks bahasa lain. interferensi dapat terjadi pada tataran fonologi, morfologi, sintaksis, semantik dan leksikon. Dalam penelitian ini, interferensi dibatasi pada tataran morfologis. Secara etimologi, morfologi berasal dari kata morf yang berarti "bentuk" dan logi yang berarti "ilmu". Jadi secara harfiah kata morfologi berarti "ilmu yang mengenai bentukbentuk dan pembentukan kata" (Chaer: 2008)

Siswa kelas VIII SMP Negeri di Kecamatan Cimanggis Kota Depok adalah termasuk usia remaja. Jika dikaitkan dengan psikologi perkembangan, pada masa remaja banyak yang menggunakan bahasa "gaul". Karakter siswa SMP memiliki perbedaan dengan kelompok lainnya, seperti kelompok orang tua, anak-ana , ibu-ibu dan sebagainya. Ada berbagai identitas yang membedakan mereka dengan kelompok masyarakat lainnya, seperti cara berpakaian, cara bergaul, bertingkah laku dan sebagainya. Salah satu perilaku yang cukup menonjol yang menjadi cirinya adalah bahasa yang digunakan. Sebagai akibatnya didalam masyarakat manapun yang memiliki kelompok remaja, akan ditemui jenis bahasa yang lazim digunakan diantara mereka sebagai bahasa pergaulan di luar lingkup situasi yang formal yang disebut bahasa gaul. Bahasa gaul para remaja dalam hal ini, termasuk ke dalam salah satu sosiolek yang faktor penentu utamanya adalah umur. Tetapi ternyata dalam pembelajaran di sekolah bahasa gaul masih mereka gunakan dalam karangan eksposisi yang menuntut penggunaan bahasa yang baku sesuai kaidah bahasa Indonesia. Dengan demikian perlu dipikirkan pemecahannya agar tujuan pembelajaran menulis eksposisi di sekolah dapat berjalan dengan optimal dan mendapatkan hasil yang optimal pula.

Tiga contoh kalimat pada kalimat dibawah ini, terjadi campuran bahasa Betawi dalam penulisan bahasa Indonesia, khususnya dalam tataran morfologi. Beberapa kalimat penulis temukan dalam penelitian sebagai berikut: (1)"Sudah-sudah gak usah marah - marah lebih baik kita rapihkan sampah-sampah ini." (2) "May, anterin aku liat pengumuman OSN, yuk!" (3) "Kamu mahemangsetiap hari lupa." Kalimat tersebut jelas merekam pemakaian bahasa sehari-hari yang digunakann oleh masyarakat. Apakah hal tersebut menunjukkan terjadinya kesenjangan antara tujuan pembelajaran bahasa dan sastra di sekolah dengan kenyataan di

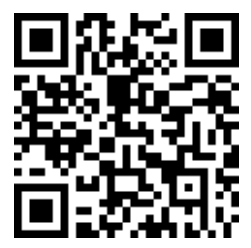

DOI PUBLIKASI https://doi.org/10.37010/int.v1i2 
lapangan. Terkadang mereka kesulitan mencari pengganti kata yang tepat. Kesulitan itu memungkinkan adanya interferensi dari bahasa Betawi. Interferensi itu dapat terjadi pada tataran linguistik, misalnya dalam aspek fonologi, morfologi, leksikal dan sintaksis.

Siswa SMP Negeri 17 Kota Depok termasuk masyarakat yang berada di lingkungan Betawi pinggiran meskipun latar belakang mereka berasal dari etnis yang berbeda. Masyarakat kecamatan Cinere dari berbagai etnis dan keseharian mereka menggunakan bahasa Betawi sekaligus dapat menggunakan bahasa Indonesia. Menurut situs https://jakarta.go.id/ bahasa Betawi masih merupakan salah satu bentuk dialek Melayu. Bahasa Betawi merupakan hasil pembauran bahasa-bahasa antar suku dan dipengaruhi unsur bahasa asing (Arab, Belanda, Portugis, Inggris, dan Cina). Bahasa Melayu dialek Betawi ini menajdi kebudayaan bagi orang Betawi dan digunakan secara turun temurun sebagai bahasa sehari-hari.

Berdasarkan kenyataan di lapangan seperti yang diuraikan maka penelitian tentang interferensi bahasa Betawi dalam karangan eksposisi Bahasa Indonesia siswa kelas VIII SMP Negeri 17 dianggap karena penting masalah interferensi ini dikaitkan dengan pembelajaran Bahasa Indonesia. Di samping itu,masalah interferensi bahasa menjadi sesuatu hal yang telah secara luas terjadi terutama di SMP dengan wilayah yang berdekatan dengan Jakarta. Interferensi bahasa Betawi untuk anak yang berada di lingkungan Kota Depok dan Jakarta akan berpengaruh pada hasil karangan eksposisi siswa.

\section{METODE}

Metode yang digunakan dalam penelitian ini adalah metode kualitatif. Endraswara (2004) membuat definisi bahwa, "penelitian kualitatif adalah penelitian yang dilakukan dengan tidak mengutamakan angka-angka, tetapi mengutamakan kedalaman penghayatan terhadap interaksi antar konsep yang sedang dikaji secara empiris". Metode penelitian bahasa berkaitan pula dengan tujuan penelitian serta melibatkan pengumpulan dan pemilihan data, penelitian ini adalah penelitian kualitatif dengan analisis isi (Content Analysis), penelitian kualitatif dengan ciri deskriptif menurut Vredenburght dalam Nyoman Khuta (2007).

Jenis penelitian ini adalah deskriptif kualitatif, yaitu penyajian data yang diperoleh berdasarkan objek penelitian. Suatu penelitian tentu diawali dengan pengumpulan data yang sesuai dengan tujuan. Oleh karena itu, objek penelitian yang penulis lakukan ialah memilah isi karangan eksoposisi yang mengandung interferensi. Menganalisis sesuai dengan tinjauan morfologi dalam hal ini adalah isi dari wacana dari karangan eksposisi.

Teknik pengumpulan data menggunakan metode simak atau penyimakan. Metode simak adalah metode pengumpulan data dengan menyimak data (Sudaryanto, 1983). Tekniknya yang digunakan yaitu metode pustaka dengan membagi wacana menjadi beberapa kalimat untuk dikelompokkan dan dianalisis berdasarkan unsur pembentuknya kemudian diteruskan menggunakan teknik dasar sadap dan teknik lanjutannya teknik catat. Teknik sadap yaitu untuk mendapatkan data pertama-tama dengan segenap kecerdikan dan kemauan menyadap dari sumber data tertulis berupa kalimat dan teknik lanjutannya adalah teknik catat

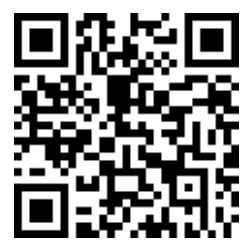

DOI PUBLIKASI https://doi.org/10.37010/int.v1i2 
yaitu pencatatan dari berbagai buku atau referensi yang berkaitan dengan interferensi. Teknik analisis data yang digunakan dalam penelitian ini dilakukan secara deskriftif dengan analisis isi (content analysis), yaitu dengan menganalisis setiap kalimat. Secara terperinci, langkahlangkah analisis data yang akan dilakukan diantaranya :

1. Menganalisis isi karangan.

2. Menentukan kalimat yang akan dianalisis.

3. Menganalisis aspek morfologi interferensi bahasa Betawi.

4. Menganalisis dari aspek morfologi.

\section{HASIL DAN PEMBAHASAN}

\section{Hasil}

Berdasarkan rekapitulasi tabel analisis di bawah ini, maka dapat diketahui hasil analisis interferensi bahasa Betawi dari bahasa Indonesia dalam karangan eksposisi siswa SMP kelas VIII terdapat sejumlah interferensi bahasa Betawi. Hal tersebut terlihat 84 kalimat dari 260 kalimat. Interferensi morfologi yang akan dianalisis meliputi unsur perubahan vokal dan konsonan, penghilangan vokal dan konsonan, penggunaan prenasal, bentuk afiksasi akhiran -in dan -an, penghilangan diftong, dan penggunaan kata lisan bahasa pertama.(Chaer, Muhajir, $2008,2000)$

Tabel 1. Rekapitulasi Hasil Analisis Morfologi

\begin{tabular}{|c|c|c|c|}
\hline 1 & $\begin{array}{l}\text { Perubahan } \\
\text { vokal dan } \\
\text { konsonan }\end{array}$ & 22 & $8.5 \%$ \\
\hline 2 & $\begin{array}{c}\text { Penghilangan } \\
\text { vokal dan } \\
\text { konsonan }\end{array}$ & 16 & $6.2 \%$ \\
\hline 3 & $\begin{array}{c}\text { Afiksasi } \\
\text { (Sufiks -an } \\
\text { dan -in) }\end{array}$ & 14 & $5.4 \%$ \\
\hline 4 & $\begin{array}{c}\text { Pengulangan } \\
\text { prenasal }\end{array}$ & 12 & $4.6 \%$ \\
\hline 5 & $\begin{array}{l}\text { Penghilangan } \\
\text { diftonng }\end{array}$ & 10 & $3.8 \%$ \\
\hline 6 & $\begin{array}{c}\text { Penggunaan } \\
\text { bahasa }\end{array}$ & 10 & $3.8 \%$ \\
\hline
\end{tabular}

DOI PUBLIKASI https://doi.org/10.37010/int.v1i2 
pertama

7
$\mathrm{Jml}$

Jml Kalimat

yang tak

8

mengandung

unsur

interferensi

Jml Kalimat
84

$32.3 \%$

176

$67.7 \%$

Jumlah kalimat seluruh adalah 720 kalimat dibagi satu pertiga yaitu didapat 240 kalimat yang di analisis.

\section{Pembahasan}

Untuk memperjelas tabel 1 berikut disajikan beberapa contoh analisis masing-masing dengan mengambil beberapa kalimat.

1. Jembatan itu rubuh disebabkan air sungai meluap.

Analisis : perubahan vokal /o/ dalam kata /roboh/menjadi /u/ pada kata

Kesimpulan:

$$
\text { /rubuh/ }
$$

Terdapat interferensi pada tataran morfologi perubahan vokal, yaitu bunyi /o/ menjadi $/ \mathrm{u} /$.

2. Saat hujan air ngeluap dari sungai.

Analisis : awalan kata kerja prenasal KD berawalan konsonan $/ \mathrm{m} /$ bervariasi dengan bentuk /nge/ sehingga menghasilkan kata ngeluap

Kesimpulan :

Meluap $=$ me+luap $=$ Nge+luap $=$ ngeluap

Terdapat interferensi prenasal morfologi dengan menambahkan /ng/ sebagai kata dasar

3. Hujan deres mengakibatkan banjir di daerah aku.

Analisis : perubahan vokal /a/ dalam kata /deras/ menjadi /e/ pada kata /deres/

Kesimpulan:

Terdapat interferensi pada tataran morfologi perubahan vokal, yaitu bunyi /a/ menjadi le/.

4. Mereka harus menaikin kendaraannya ke atas getek agar tidak megalami kemogokan. Analisis : bentuk

me+KD+in

DOI PUBLIKASI https://doi.org/10.37010/int.v1i2 
Me+naik+in = menaikin

/getek/ berasal dari bahasa pertama yang mempengaruhi pembendaharaan kata Kesimpulan : bahasa kedua.

Terdapat Interferensi morfologi dengan menggunakan imbuhan akhiran /in/

Menggunakan kata /getek/ yang merupakan B1

5. Semaleman hujan terus menerus turun.

Analisis : perubahan vokal /a/ pada kd /malam/ menjadi /e/ pada kata

$$
\begin{aligned}
& \text { /malem/ } \\
& \text { bentuk se+KD+an } \\
& \text { Se+malem+an = semaleman }
\end{aligned}
$$

Kesimpulan:

Terdapat interferensi pada tataran morfologi perubahan vokal, yaitu bunyi /a/ menjadi le/.

6. Hujan deras disertai angin yang kenceng.

Analisis : perubahan vokal /a/ dalam kata /kencang/ menjadi /e/ pada kata

$$
\text { /kenceng/ }
$$

Kesimpulan:

Terdapat interferensi pada tataran morfologi perubahan vokal, yaitu bunyi /a/ menjadi /e/.

7. Warga harus berhati-hati agar tidak kepeleset.

Analisis : bentuk

$$
\mathrm{ke}+\mathrm{KD}
$$

$\mathrm{Ke}+$ peleset= kepeleset

Kesimpulan :

Terdapat interferensi pada tataran morfologi penambahan vokal/ e/.

8. Mobil dan motor nekat nerobos banjir.

Analisis : bentuk $\mathrm{N}+\mathrm{KD}$

$$
\mathrm{Ne}+\text { terobos }=\text { nerobos }
$$

Terdapat perubahan fonem /t/ menjadi /n/

Kesimpulan:

Terdapat interferensi morfologi pada tataran perubahan konsonan, yaitu bunyi /t/ menjadi /n/.

9. Selama tiga hari hujan ngeguyur ibukota Jakarta.

DOI PUBLIKASI https://doi.org/10.37010/int.v1i2 
Analisis : awalan kata kerja prenasal KD berawalan konsonan /g/

bervariasi dengan bentuk /nge/ sehingga menghasilkan kata ngeguyur

$$
\text { guyur }=\text { nge }+ \text { guyur }=\text { ngeguyur }
$$

Kesimpulan :

Terdapat interferensi morfologi prenasal dengan menambahkan /ng/ sebagai kata dasar

10. Air ngenenggelemin rumah dan pohon-pohon.

Analisis : awalan kata kerja prenasal KD berawalan konsonan /t/

bervariasi dengan bentuk /nge/ sehingga menghasilkan kata nngenenggelemin

tenggelam $=$ nge + tenggelam + in $=$ ngenenggelamin

menambahkan imbuhan akhiran -in

Kesimpulan :

Terdapat interferensi morfologi prenasal dengan menambahkan /ng/ sebagai kata dasar

Terdapat Interferensi morfologi dengan menggunakan imbuhan akhiran /in/

11. Pantai yang awalnnya tenang mengakibatkan prahu terbalik dan ancur.

Analisis : penghilangan fonem /e/ pada kata /perahu/menjadi /prahu/

Kesimpulan :

Penghilangan fonem /h/ pada kata /hancur/ menjadi /ancur/

Terdapat interferensi morfologi penghilangan fonem $/ \mathrm{h} /$

12. Untung aja saya membawa jas hujan jadi saya tidak keujanan.

Analisis : penghilangan fonem /a/ pada kata /saja/ menjadi /aja/

Penggunakan frase untung saja bersifat lisan dan menghilangkan imbuhan /ber/

Kesimpulan :

Penghilangan fonem $/ \mathrm{h} /$

Terdapat interferensi morfologi penghilangan imbuhan ber- menjadikan kata bersifat lisan.

Terdapat interferensi pada tataran morfologi penghilangan fonem /s/

13. Saya bingung pengin cari tempat neduh.

Analisis : bentuk

pe+KD

Pe+ingin $=$ pengin

Penghilangan fonem /i/ pada kata /ingin/

Perubahan fonem /t/ menjadi /n/ dalam kata /teduh/ menjadi

/neduh/

Kesimpulan :

Terdapat interferensi morfologi perubahan fonem vokal/i/

Terdapat interferensi morfologi perubahan fonem konsonan /t/

DOI PUBLIKASI https://doi.org/10.37010/int.v1i2 
14. Pakaian ku mulai lepek karna keujanan.

Analisis : frasa lisan frasa pertama dimasukkan kedalam kalimat.

$$
\begin{aligned}
& \text { Penghilangan fonem vokal /e/ } \\
& \text { Penghilangan fonem konsonan /h/ }
\end{aligned}
$$

Kesimpulan :

Terdapat interferensi morfologi bahasa pertama lisan dimasukkan kedalam kalimat

Terdapat interferensi morfologi penghilangan fonem vokal dan konsonan

15. Seringnya hujan deres dan sering mampetnya saluran pembuangan atau mengakibatkan banjir besar.

Analisis : perubahan vokal /a/ dalam kata/deras/menjadi /e/ pada kata /deres/

Kesimpulan :

Penggunaan bahasa lisan /mampet/ dan perubahan vokal /a/menjadi /e/

Terdapat interferensi morfologi perubahan vokal

Terdapat interferensi morfolongi penggunaan bahasa lisan

16. Jembatan rubuh karna kencengnya tiupan angin.

Analisis : perubahan vokal/o/ dalam kata /roboh/menjadi /u/ pada kata

$$
\text { /rubuh/ }
$$

Kesimpulan :

Terdapat interferensi morfologi perubahan vokal

17. Banyak korban yang kejatohan jembatan yang ambruk.

Analisis : bentuk $\mathrm{ke}+\mathrm{kd}$

perubahan vokal /a/ menjadi /o/

$$
\text { ke+jatoh }+\mathrm{an}=\text { kejatohan }
$$

Kesimpulan :

Terdapat interferensi morfologi vokal

18. Air pun makin lama makin ninggiin.

Analisis : perubahan fonem /t/ menjadi /n/ dan penambahan akhiran -in

$$
(/ \mathrm{t} / \text { )ninggi }+ \text { in }=\text { ninggin }
$$

Kesimpulan :

Terdapat interferensi morfologi perubahan fonem

DOI PUBLIKASI https://doi.org/10.37010/int.v1i2 
Terdapat interferensi morfologi penambahan akhiran

19. Dari pagi sampe malem hujan tidak berhenti.

Analisis : perubahan diftong /ai/ menjadi /e/ dari kata /sampai/ menjadi /sampe/

Kesimpulan :

Terdapat penghilangan diftong

20. Banjir tersebut mengakibatkan rumah terendem aer.

Analisis : perubahan vokal /a/ menjadi /e/ dari kata /rendam/ menjadi

morfologi /rendem/

Perubahan fonem vokal /i/ menjadi /e/

Kesimpulan :

Terdapat interferensi morfologi perubahan fonem vokal

21. Biasanya banjir melanda pemukiman warga yang sempit yang jarang terdapat lobang untuk penampungan air.

Analisis : perubahan vokal /u/ menjadi /o/ dari kata /lubang/ menjadi

/lobang/

Kesimpulan :

Terdapat interferensi morfologi perubahan fonem vokal

22. Selang beberapa hari hujan pun kembali melanda malahan sekarang lebih parah dari sebelumnya.

Analisis : penambahan akhiran -an pada kata malah

Kesimpulan :

Terdapat interferensi morfologi penambahan akhiran -an

23. Banyak jembatan ancur karna turun hujan dan orang pun takut ketiban jembatan.

Analisis : penghilangan konsonan /h/ dari kd /hancur/menjadi /ancur/

Penghilangan vokal /e/ dari kd /karena/ menjadi /karna/

Kesimpulan :

Terdapat interferensi morfologi penghilangan konsonan $/ \mathrm{h} /$

Terdapat interferensi morfologi penghilangan vokal

24. Saking derasnya arus sungai sama kali yang meluap jembatan pun roboh.

Analisis : pelafan lisan yang dituliskan akibat pemerolehan bahasa

pertama terbawa pada pelafalan bahasa kedua. /saking/ memiliki pengertian yang sepadan dalam bahasa Indonesia yaitu /sangat/. 
25. Pada hari slasa terjadi hujan lebat di daerah ibukota Jakarta.

Analisis : penghilangan vokal /e/ dari kd /selasa/ menjadi /slasa/

Pelafalan lisan yang dituliskan karena pemerolehan bahasa pertama

Kesimpulan :

terbawa pada pelafalan bahasa kedua.

Terdapat interferensi morfologi penghilangan vokal

26. Seperti pergi ke kantor, brangkat ke sekolah.

Analisis : penghilangan vokal /e/ dari imbuhan /ber/ menjadi brangkat.

Kesimpulan :

Terdapat interferensi morfologi penghilangan vokal

27. Maka warga memperbaikin jembatan yang roboh tersebut.

Analisis : menambahkan imbuhan akhiran -in

Memper+baik+in $=$ memperbaikin

Kesimpulan :

Terdapat interferensi morfologi penambahan akhiran -in

28. Ruas jalan dan plosok Jakarta terendam banjir.

Analisis : penghilangan vokal /e/ dari kd /pelosok/

Kesimpulan :

Terdapat interferensi morfologi penghilangan vokal

29. Hujan deras mengakibatkan perahu menjadi tebalik.

Analisis : bentuk

$\mathrm{ke}+\mathrm{KD}$

te+balik =tebalik

Kesimpulan :

Terdapat interferensi morfologi penghilangan konsonan

30. Hujan kali ini bener-bener menyebabkan banyak musibah.

Analisis : perubahan vokal /a/ dr kd/benar/menjadi /bener/

Terdapat pengulangan kata /bener/ menjadi /bener-bener/

Kesimpulan :

Terdapat interferensi morfologi perubahan fonem vokal

Berdasarkan analisis aspek interferensi morfologi yang sering muncul adalah perubahan vokal dan konsonan digunakan oleh peserta didik sebanyak 22 kali atau 8.5\%. Penghilangan vokal dan konsonan yang digunakan peserta didik sebanyak 16 kalimat atau 6.2\%. Bentuk afiksasi awalan dan akhiran digunakan peserta didik sebanyak 14 kalimat atau 5.4\%.

Penggunaan prenasal digunakan peserta didik sebanyak 12 kalimat atau 4.6\%. Penghilangan diftong oleh peserta didik sebanyak $10 \mathrm{kali}$ atau 3.8\%. Penggunaan bahasa pertama yang digunakan peserta didik sebanyak 10 kali atau $3.8 \%$.

\section{PENUTUP}

DOI PUBLIKASI https://doi.org/10.37010/int.v1i2 
Hasil penelitian terhadap interferensi bahasa Betawi dari bahasa Indonesia dalam karangan eksposisi siswa SMP kelas VIII berdasarkan tataran morfologi yang telah dilakukan ini, dapat diambil suatu simpulan sebagai berikut :

1. Hasil analisis menunjukkan bahwa isi karangan eksposisi kelas VIII untuk sisiwa yang bersekolah daerah pinggiran Jakarta memiliki interferensi bahasa Betawi.

2. Interferensi morfologi yang ditemukan pada karangan eksposisi siswa SMP kelas VIII meliputi perubahan vokal dan konsonan, penghilangan vokal dan konsonan, penggunaan prenasal, bentuk afiksasi akhiran -in dan -an, diftong, dan penggunaan kata lisan bahasa pertama

3. Unsur morfologi yang ditemukan terdapat di 84 kalimat dalam 260 kalimat atau dapat di persentasekan sebesar 32,3\%.

4. Aspek interferensi morfologi yang sering muncul adalah perubahan vokal dan konsonan digunakan oleh peserta didik sebanyak 22 kalimat atau 8.5\%. Penghilangan vokal dan konsonan yang digunakan peserta didik sebanyak 16 kalimat atau $6.2 \%$. Bentuk afiksasi awalan dan akhiran digunakan peserta didik sebanyak 14 kalimat atau 5.4\%. Penggunaan prenasal digunakan peserta didik sebanyak 12 kalimat atau $4.6 \%$. Sedangkan yang paling sedikit adalah penghilangan diftong dan penggunaan bahasa pertama yang digunakan siswa sebanyak 10 kali atau 3.8\%.

Menyadari masih terbatasnya penelitian di bidang linguistik yang mengambil sasaran karangan sebagai bahan kajian maka perlu kiranya penelitian ini lebih diintensifkan. Khususnya guru bahasa Indonesia sebaiknya melakukan penelusuran kompetensi yang intensif sebelum memberikan materi pembelajaran. Dengan mengetahui kompetensi yang masih belum dikuasai siswa, proses pembelajaran akan lebih fokus, efektif, dan efisien serta memperoleh hasil pembelajaran yang memuaskan. Dan para siswa diharapkan dapat mengembangkan penguasaan kalimat dalam rangka meningkatkan kemampuan menulis karangan eksposisi.

\section{DAFTAR PUSTAKA}

Alwasilah, A Chaedar. (1985). Beberapa Madhab dan dikotomi Teori Linguistik. Bandung: Angkasa

Brown, H. (2001). Teaching by Principles: An Interactive Approach to Language Pedagogy Second Edition. White Plains, NY: Addison-Wesley.

Chaer, A. (1976). Kamus Dialek Melayu Jakarta-Bahasa Indonesia. Jakarta: Nusa Indah

Chaer, A. (2008). Morfologi Bahasa Indonesia. (Pendekatan Proses). Jakarta: Rineka Cipta

Chaer, A dan Leoni Agustina. (2002). Sosiolinguistik Perkenalan Awal. Jakarta: Rineka Cipta

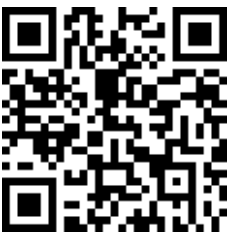

DOI PUBLIKASI https://doi.org/10.37010/int.v1i2 
Chaer, A. (2002). Psikolinguistik, Kajian Teoretik. Jakarta: PT. Asdi Mahasatya

Endraswara, Suwardi. (2003). Metodologi Penelitian Sastra. Yogyakarta: Pustaka

Nababan, PWJ. (1986). Sosiolinguistik Suatu Pengantar. Jakarta: PT Gramedia

Muhadjir. (2000) Bahasa Betawi Sejarah dan Perkembangannya. Jakarta: Yayasan Obor Indonesia

Muhadjir (1984). Morfologi Dialek Jakarta Afiksasi dan Reduplikasi. Jakarta: Djambatan, 1984

Semi, A. (2007). Dasar-dasar Keterampilan Menulis. Bandung: Angkasa

Sudaryanto. (1993). Metode dan Aneka Teknik Analisis Bahasa. Yogyakarta: Duta Wacana University Press

Ratna, S.U. (2007). Teori Metode dan Teknik Penulisan Sastra. Yogyakarta: Pustaka Pelajar Weinreich, Uriel. (1970). Languange in Contact. The Hague: Mouton

Bahasa Betawi. . (1 Januari 2017). https://jakarta.go.id/artikel/konten/2576/bahasabetawi\#: :text=Termasuk\%20salah\%20satu\%20bentuk\%20dialek,lain\%20yang\%20paham\%20 bahasa\%20Indonesia. Bahasa diakses 15 Maret 2021 